\title{
The Benthic Boundary Layer: geochemical and oceanographic data from the GEOSTAR-2 Observatory
}

\author{
Giuseppe Etiope $\left({ }^{1}\right)$, Paolo Favali $\left({ }^{1}\right)$, Jean-Luc Fuda $\left({ }^{2}\right)$, Francesco Italiano $\left({ }^{3}\right)$, Matthias Laubenstein $\left({ }^{4}\right)$, \\ Claude Millot $\left({ }^{5}\right)$ and Wolfango Plastino $\left({ }^{1}\right)\left({ }^{6}\right)$ \\ (1) Istituto Nazionale di Geofisica e Vulcanologia, Sezione di Roma 2, Roma, Italy \\ (2) Centre d'Océanologie de Marseille (COM), CNRS, Marseille, France \\ $\left(^{3}\right)$ Istituto Nazionale di Geofisica e Vulcanologia, Sezione di Palermo, Italy \\ $\left({ }^{4}\right)$ Istituto Nazionale di Fisica Nucleare (INFN), Laboratori Nazionali del Gran Sasso, Assergi (AQ), Italy \\ $\left(^{5}\right)$ Laboratoire de Oceanographie et de Geochimie (LOB), La Seyne-sur-Mer, France \\ ${ }^{(}{ }^{6}$ Dipartimento di Fisica, Università degli Studi Roma Tre, Roma, Italy
}

\begin{abstract}
Geochemical and oceanographic data, acquired throughout 6 months by the GEOSTAR-2 benthic observatory in Southern Tyrrhenian Sea, disclosed ocean-lithosphere interactions in the 1900-m deep Benthic Boundary Layer (BBL), distinguishing two water masses with different origin and, possibly, benthic residence time. Gas concentration, helium isotopic ratios, radioactivity, temperature, salinity and vertical component of the current converged towards the indication of a BBL characterised by a colder and fresher Western Water (WW), episodically displaced by the cascading of the warmer and saltier Eastern Overflow Water (EOW). The benthic WW has a higher concentration of geochemical tracers diffusing from the seafloor sediments. The data set shows the potential of long-term, continuous and multiparametric monitoring in providing unique information which cannot be acquired by traditional, short-term or single-sensor investigations.
\end{abstract}

Key words Benthic Boundary Layer - deep-seafloor - ocean temperature - helium - ocean radioactivity

\section{Introduction}

The Benthic Boundary Layer (BBL) is the dynamic interface between the lithosphere (seafloor) and the ocean (seawater) where many physical, geochemical and biological processes play an important role in environmental global

Mailing address: Dr. Giuseppe Etiope, Istituto Nazionale di Geofisica e Vulcanologia, Sezione di Roma 2, Via di Vigna Murata 605, 00143 Roma, Italy; e-mail: etiope@ingv.it changes (Boudreau and Jorgensen, 2000). Geohazards, carbon cycle, heat flow, life generation, climatic oceanography, are only some examples of local or global processes whose understanding is today limited due to the lack of data related to the deep ocean floors (Thiel et al., 1994). Lithospheric processes at the BBL impact the marine environment at different temporal and spatial scales. Earthquakes produce short-term effects (landslides and tsunamis) that threaten the lives and economy of coastal communities, while the emission of greenhouse gases and mineral-rich fluids impact long-term global climates and the formation of economically important mineral resources. The BBL has an important role on carbon cycle being either a potential sinking or transition zone for carbon coming from shallower zones of from the lithosphere. 
Oil platforms are sited on the BBL, and cables and pipelines are lain across it. Delicate marine ecosystems have evolved in this extreme environment, yet it may be significantly affected by man's activities. The BBL dynamics however is not completely clear: it is not known how it is perturbed by energy and mass release from the seabed (seismicity, heat flow, gas diffusion, biological productivity, diagenetic reactions), what distances the particles and bottom waves can be transported, what is the evolution and fate of bottom currents and storms.

The deep-sea observation and monitoring systems developed in the last decade, in the framework of technological and scientific projects in Japan, US, and Europe (Beranzoli et al., 2002, and references therein) can contribute to cover such a scientific gap.

GEOSTAR-2 (GEophysical and Oceanographic STation for Abyssal Research) is the first European deep-sea observatory for geophysical and environmental monitoring at the seabed becoming operative in 2000. It was deployed in September 2000 from the Italian R/V Urania, in the Southern Tyrrhenian Sea, between the is-

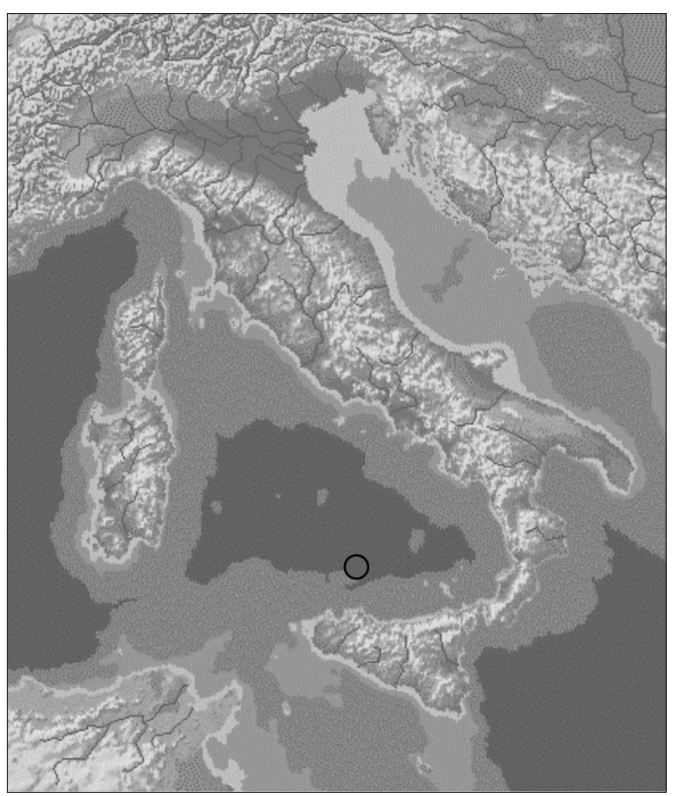

Fig. 1. Location of the GEOSTAR-2 deployment site. lands of Sicily and Ustica, at about $1900 \mathrm{~m}$ b.s.l. (fig. 1). This area was chosen as a key site for Tyrrhenian seismicity and oceanographic studies (Beranzoli et al., 1998). The sensors used for this mission (2 magnetometers, a gravitymeter, an hydrophone, a Doppler currentmeter, a singlepoint currentmeter, an automatic water sampler for laboratory geochemical analysis, a CTD and a transmissometer) were continuously controlled and managed by a data acquisition and control system able to transmit the data via surface buoy and radio or satellite link to on-shore operators. After 206 days the observatory was recovered in April 2001. More than $4100 \mathrm{~h}$ of data were recorded continuously. This mission represented the longest experiment using a complex module, with an intelligent unit, deployed at great depth.

This paper presents geochemical and oceanographic data obtained from the automatic water sampler, the CTD and the Acoustic Doppler Current Profiler (ADCP) to show how multidisciplinary and integrated monitoring at deep BBLs may provide various original and unique information, which cannot be acquired by traditional, short-term or single-sensor recordings. Specifically, temperature, salinity, light transmission, currents, radionuclides and gases, including helium isotopes, have been examined to trace environmental changes in the benthic boundary seawater.

\section{Monitoring and data acquisition}

Geochemical data refer to laboratory analyses carried out on 23 water samples collected by the GEOSTAR automatic sampler (RAS-500 McLane) from 26 September 2000 to 9 April 2001. The sampler, using aluminium bags and a pressure compensation system, was programmed for sampling every 10 days over 240 days. Four samples were duplicated and the sequence is composed of 19 time-series data (one sample was lost due to bag rupture). The sampling port was positioned at $\sim 1 \mathrm{~m}$ from the seabed.

The seawater samples have been analysed for the following parameters:

- gas concentration: $\mathrm{CO}_{2}, \mathrm{CH}_{4}, \mathrm{He}, \mathrm{Ne}$;

- helium isotopic composition: $\mathrm{R} / \mathrm{Ra}\left({ }^{3} \mathrm{He} /\right.$ ${ }^{4} \mathrm{He}$ sample $/{ }^{3} \mathrm{He} /{ }^{4} \mathrm{He}$ atm); 
- radioactivity $\left({ }^{226} \mathrm{Ra},{ }^{235} \mathrm{U},{ }^{234 \mathrm{~m}} \mathrm{~Pa},{ }^{228} \mathrm{Ra},{ }^{228} \mathrm{Th}\right.$, ${ }^{137} \mathrm{Cs}$ and $\left.{ }^{60} \mathrm{Co}\right)$.

$\mathrm{CO}_{2}$ and $\mathrm{CH}_{4}$ were analyzed by gas chromatography with micro-TCD (thermal conductivity detector; Etiope, 1997). Helium analysis was carried out with a Perkin Elmer 8500 gaschromatograph (Flame Ionization Detector and Hot Wire Detector; 5 ppmv as detection limit; analytical errors of $\pm 5 \%$ ). The ${ }^{3} \mathrm{He} /{ }^{4} \mathrm{He}$ isotopic ratio, was determined by a static mass spectrometer (VG5400TFT, VG Isotopes; typical uncertainties are about $\pm 1 \%$ for ${ }^{3} \mathrm{He} /{ }^{4} \mathrm{He}$ ratios in the range of atmospheric values; below $\pm 0.1 \%$ for high $-{ }^{3} \mathrm{He}$ samples and below $\pm 3 \%$ for low $-{ }^{3} \mathrm{He}$ radiogenic samples).

The analysis of radionuclides was carried out by gamma spectrometry with coaxial High Purity Germanium (HPGe) detectors having volumes ranging from 200 to $500 \mathrm{~cm}^{3}$ and a total background rate in the energy range $[(60 \div 2700) \mathrm{keV}]$ varying from $(221 \pm 2)$ to $(980 \pm 10)$ counts/days depending on the detector (Arpesella, 1996). Each seawater sample was measured for about ten days using a polystyrene box of $70 \mathrm{~mm}$ diameter and $30 \mathrm{~mm}$ height (Plastino et al., 2003).

Temperature and salinity were recorded by a high accuracy and stability CTD (SBE-16 SEACAT, Sea-Bird Electronics, Inc.; nominal accuracy-stability/month of $5 \times 10^{-3}-2 \times 10^{-4 \circ} \mathrm{C} /$ $5 \times 10^{-4}-3 \times 10^{-4} \mathrm{~S} / \mathrm{m}$, equipped with a pump and a quartz pressure sensor, resolution $0.01 \mathrm{ppm}$, repeatability $0.005 \% \mathrm{FS}$ ) positioned at $\sim 1 \mathrm{~m}$ from the seabed. Calibrations of temperature and conductivity sensors performed by the manufacturer before and after the mission indicate no significant drifts and guarantee the values accuracy. Seawater turbidity was monitored by a $0.25-\mathrm{m}$-pathlength transmissometer, Alphatracka Mk II (Chelsea Instruments Ltd.). The sampling rate was one sample per hour.

Current magnitude and direction were monitored by a $300 \mathrm{kHz}$ Acoustic Doppler Current Profiler. It provides $\sim 120$-m 3D current profiles, representative of water layers (cells) 3$\mathrm{m}$ thick located at increasing vertical distances from the ADCP. The ADCP was configured for providing hourly profiles resulting from the average of 100 pings evenly transmitted during $10 \mathrm{~min}$. The first cell was $\sim 7 \mathrm{~m}$ above the seafloor.

\section{Results}

\subsection{Pressure, temperature, salinity and light transmission}

The pressure sensor was confirmed to be a highly performing tide gauge, being able to sense sea level variations of a few $\mathrm{mm}$ at $\sim 1900 \mathrm{~m}$. In addition to the expected semi-diurnal and diurnal tidal signals, long term variations, as well as what can probably be interpreted as high frequency signals non-correctly resolved (the 1-h sampling was too large in this respect), can be evidenced (fig. 2a).

The most remarkable characteristics regarding the temperature and salinity records (fig. 2b,c) resides in the almost regular occurrence, roughly every 2-3 weeks, of sharp peaks deviating from the background $\left(T: 13.05^{\circ} \mathrm{C}, S: 38.51 \mathrm{psu}\right)$ with values up to $13.45^{\circ} \mathrm{C}$ and 38.63 psu, respectively. On the basis of $T-S$ peak height, duration and density variations (fig. $2 \mathrm{~d}$ ) we recognise seven major events occurring on 24 October 2000, 14 and 30 November 2000, 9 and 25 January 2001, 10 and 26 February 2001. These events appear perfectly coherent with the stratification reported in the region 10 years ago (Sparnocchia et al., 1999) and characterized, below $1500 \mathrm{~m}$, by $T-S$ gradients of the order of $0.1^{\circ} \mathrm{C} / 100 \mathrm{~m}$ and $0.02 \mathrm{psu} / 100 \mathrm{~m}$. These $T$-S peaks suggest a rapid (hours/days) lowering of the interface separating the relatively warm and saline waters of eastern origin (the socalled Eastern Overflow Water, EOW), cascading from the Channel of Sicily, from the underlying waters of western origin (Fuda et al., 2002), sampled most of the time by GEOSTAR.

Sporadic light transmission drops represented by a unique hourly data point were recorded, with a large part of spike-like events; they are expected to be due to isolated large-size particles (fig. 2e). A dramatic few-hour drop down to $3.7 \mathrm{~V}$ (i.e. a relative light transmission loss of $\sim 15 \%$ ) occurred on October 24, 2000, following several weaker events during the preceding days and coinciding with the first major $T-S$ peak. Other events coincide mainly with $T-S$ peaks of 9 and 25 January and 10 February. However, while most of the $T-S$ peaks can be associated with transmissometer peaks, many transmissometer peaks are not associated with significant $T-S$ ones. 


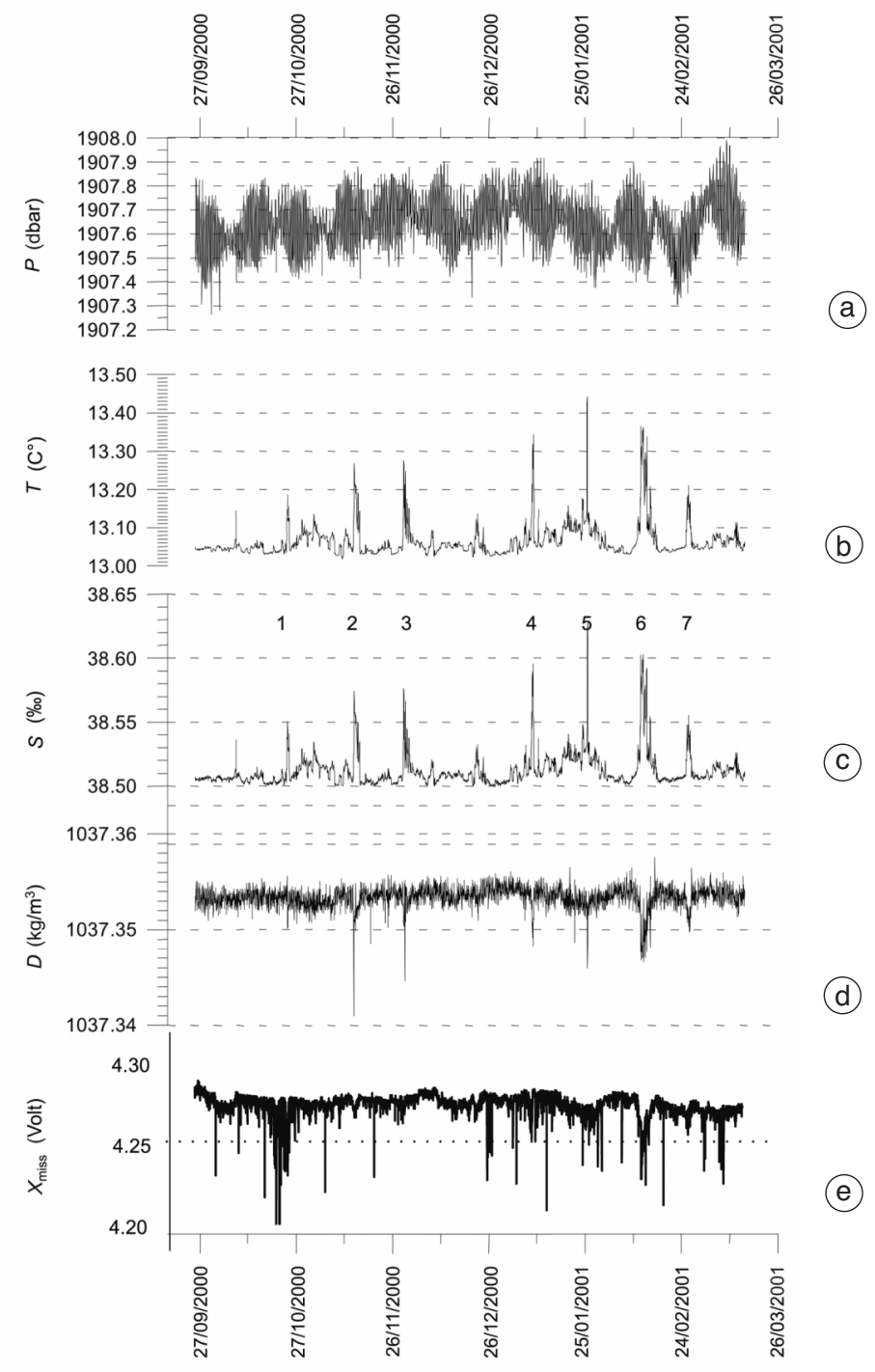

Fig. 2a-e. CTD data: a) pressure; b) potential water temperature; c) salinity; d) density; e) light transmission. The major 7 events are numbered over the salinity curve.

\subsection{Currents}

The ADCP provided different information on the deep-water circulation and on its evolution throughout 6 months. The horizontal speed (not shown) displays peaks that are very similar to the $T-S$ ones. For the purpose of this paper, we mention only that significant vertical com- ponents of current were recognised associated with the $T$-S peaks. A noticeable anomaly is the occurrence of permanent downward velocities of the order of a few $\mathrm{mm} / \mathrm{s}$ at all depths. Even though relatively weak, this background residual is a priori abnormal as vertical velocities (either upward or downward) are not expected near the seafloor, except during specific transi- 
tory processes, and except if there is a marked slope of the bottom, or up to a few meters above the seafloor where the observatory was demonstrated to deflect the flow and to induce upward motions (Fuda et al., unpublished data).

The observed vertical velocities depend on both the current direction and the current speed. For a given current direction, the higher the horizontal speed, the higher the vertical velocity.

\subsection{Gases and radionuclides}

Figure 3 shows the pattern of dissolved $\mathrm{CH}_{4}$ and $\mathrm{CO}_{2}$ throughout the mission. Their concentrations are coherently close to the theoretical atmospheric equilibrium level (ASW, Air Satu- rated Water) at the seafloor conditions, suggesting that no significant external gas sources exist. All bottles, except two (as control samples), were initially conditioned by adding $0.1 \% \mathrm{Hg}$ $\mathrm{Cl}_{2}$ to prevent bacterial consumption of $\mathrm{CH}_{4}$. As expected, the two non-conditioned samples displayed no $\mathrm{CH}_{4}$ concentration (or it was below the detection limit). Figure 4 shows the variation of helium concentration and its isotopic ratio $\left({ }^{3} \mathrm{He} /{ }^{4} \mathrm{He}\right)$. Although $\mathrm{He}$ isotopes were measured only in 11 samples, the ${ }^{3} \mathrm{He} /{ }^{4} \mathrm{He}$ ratio coupled with $\mathrm{He} / \mathrm{Ne}$ ratio suggested clearly the distinction of two different waters, as shown in fig. 5. Five water samples showed a significant enrichment of radiogenic $\mathrm{He}$ (low ${ }^{3} \mathrm{He}$ content) and these samples have also higher He mass concentration (mean of $3.2 \mathrm{ppmv}$ ) respect to

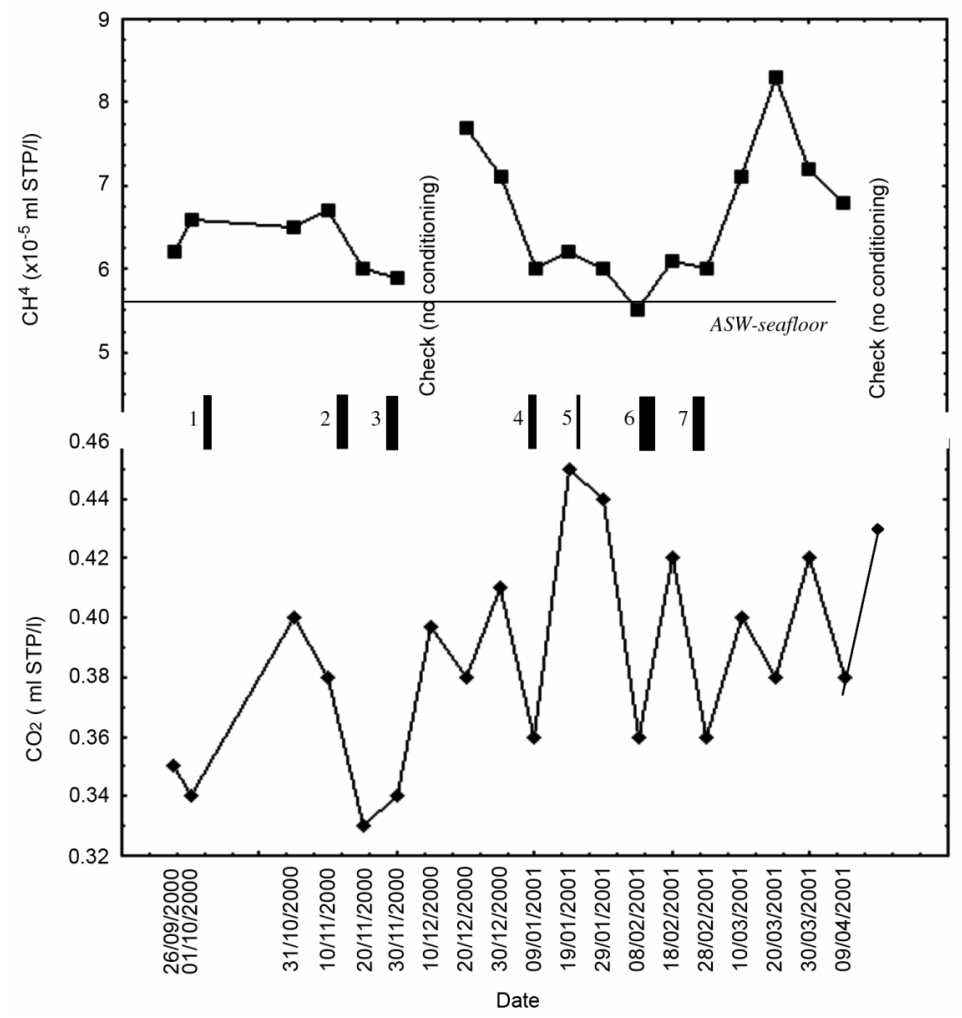

Fig. 3. $\mathrm{CO}_{2}$ and $\mathrm{CH}_{4}$ variation. Vertical bars are the seven main $T / S$ events marked in fig. 2a-e. ASW is the Air Saturated Water (equilibrium with the atmosphere calculated at seafloor conditions). Checks are the samples where no preservative was used and therefore all $\mathrm{CH}_{4}$ was consumed by biodegradation. 


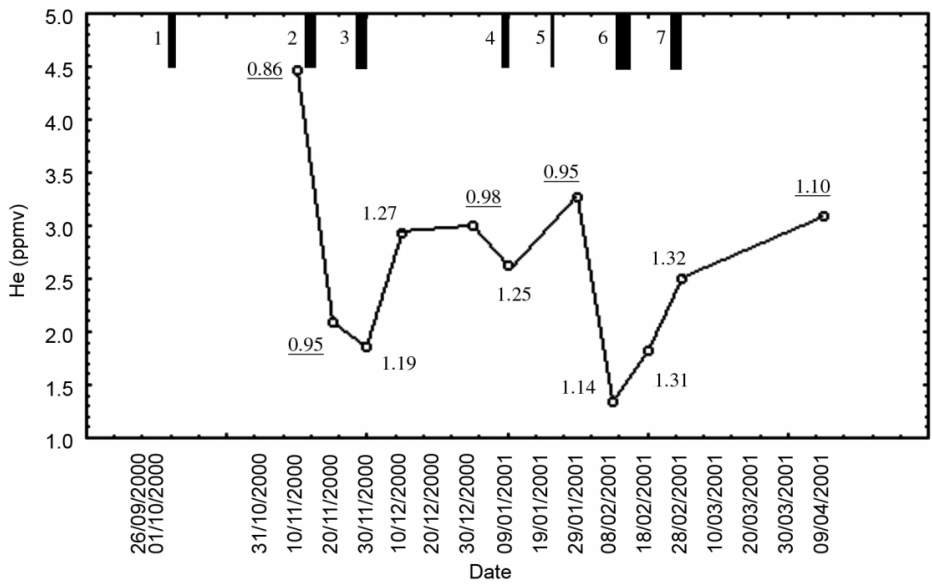

Fig. 4. Helium variation. ${ }^{3} \mathrm{He} /{ }^{4} \mathrm{He}$ ratio $\left(\times 10^{-6}\right)$ is reported for each data point. Underlined ratios are those of the bottom-water group identified in fig. 5 .

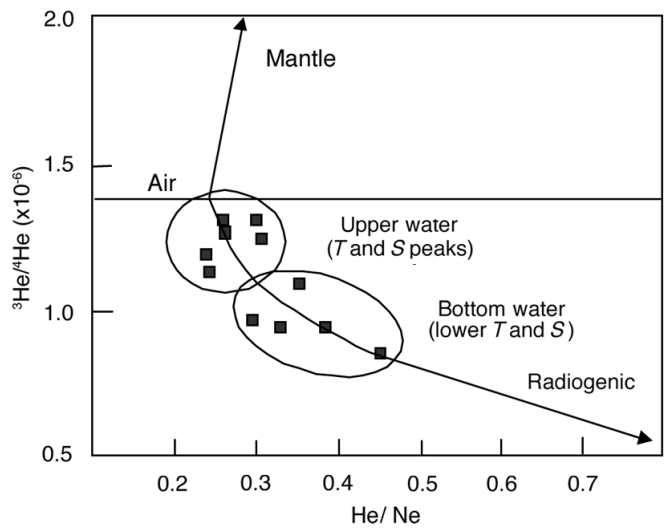

Fig. 5. Helium isotope ratio versus $\mathrm{He} / \mathrm{Ne}$. The plot indicates two different waters probably linked to the different water masses whose interface oscillates producing $T / S$ peaks. The isotope ratio of $1.4 \times 10^{-6}$ is that of the atmosphere. Samples closer to this ratio indicate major atmospheric signal (shallower water). Lower ratios are along the mixing line with crustal (radiogenic) sources, and this can be indicative of bottom water, closer to seafloor, with higher residence time.

the others (2 ppmv). The lower ${ }^{3} \mathrm{He}$ content is also indicative of lower tritiugenic ${ }^{3} \mathrm{He}$, produced by tritium decay within the water column.
The radioactivity data are coherent with this pattern (figs. 6 and 7). The same group of samples having lower gas content and less radiogenic helium display drops of radioactivity for all radionuclides with typical values of standard seawater (Inn et al., 2001).

\section{Discussion}

Physico-chemical and oceanographic data (one sample per hour) show a fair relationship between temperature/salinity, turbidity peaks and vertical movement and horizontal speed of water masses. The ADCP confirms the interpretation of CTD data regarding the existence of two water masses as it sensed the interface motions, with remarkable dynamic features found coincident with the $T$-S peaks. As also supported by previous local CTD stratification profiles, it is most likely that this correlation is consistent with rapid lowering of the interface separating the warm, saline and more turbid waters of eastern origin (the so-called Eastern Overflow Water, EOW), cascading from $400 \mathrm{~m}$ in the Channel of Sicily, from the underlying colder waters of western origin (WW), that are also «quiet» and hence not turbid, sampled most of the time by GEOSTAR. 


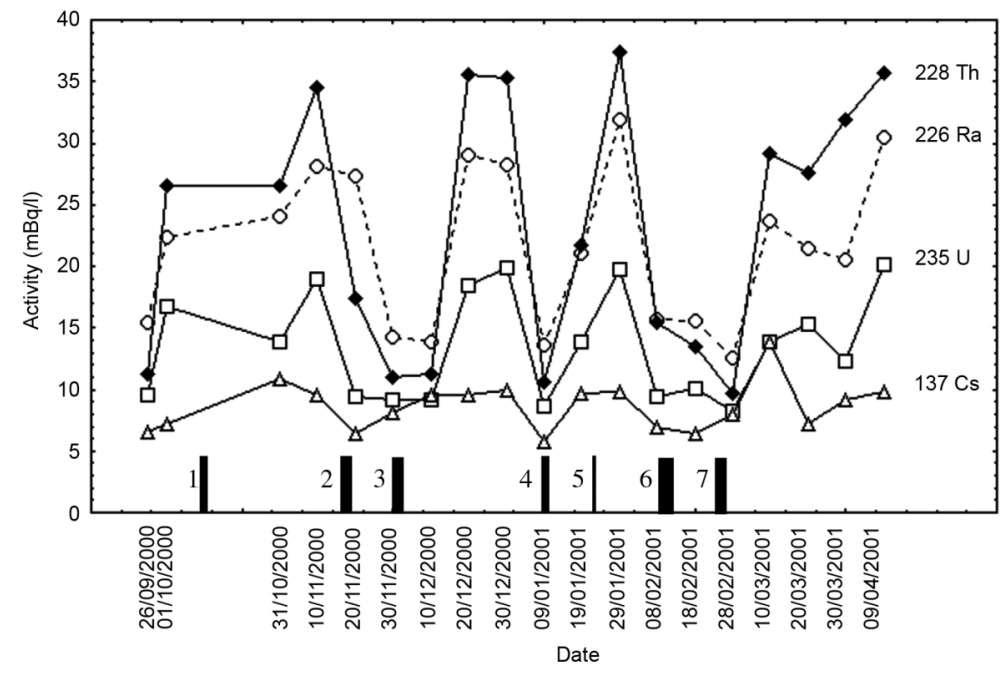

Fig. 6. Variation of activity of some radionuclides. Lower activities correspond to $T / S$ peaks and are indicative of shallower water mass, as suggested by helium and its isotopic ratio.

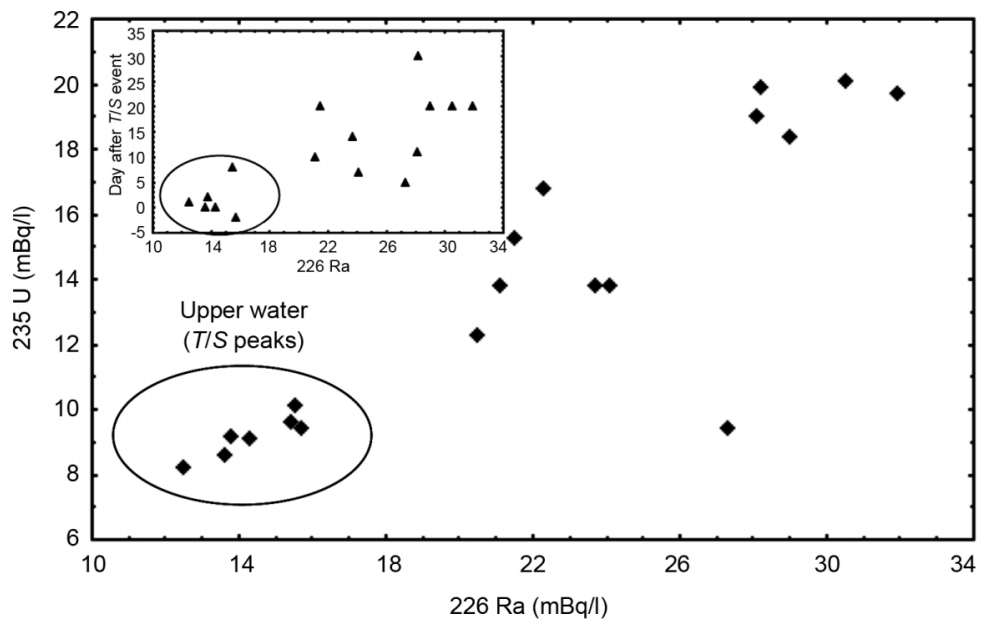

Fig. 7. ${ }^{235} \mathrm{U}$ versus ${ }^{226} \mathrm{Ra}$. A group of lower activity is distinguished, referring to samples closer to $T / S$ peaks, in perfect analogy with fig. 5. The smaller plot shows the clustering in relation to the temporal distance (in days) of water sampling after a $T / S$ event.

The main result of geochemical analyses is the sharp distinction of two geochemically different water masses, as suggested by He isotopes (fig. 5) and radionuclides (fig. 7).
The main problem is the comparison between geochemical and hydrographic data, due to the limited availability of water samples for laboratory analysis, whose collection followed 


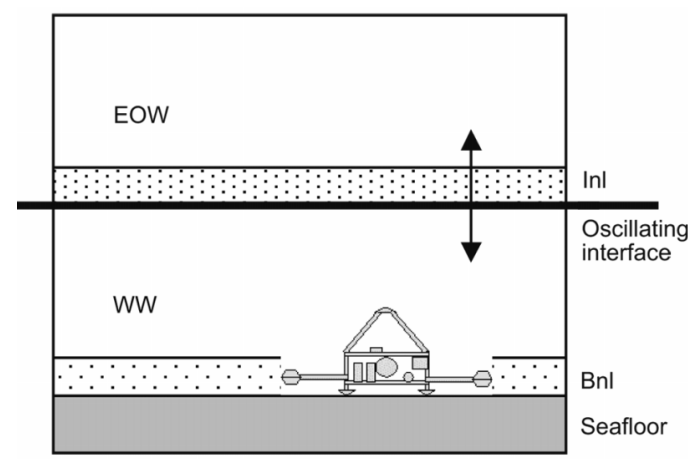

Fig. 8. Sketch of the oscillating water mass interface in the BBL. EOW - Eastern Overflow Water; WW - Western Water; bnl - benthic nepheloyd layer; inl - intermediate nepheloyd layer. GEOSTAR detected WW for most of the time and events of EOW cascading, as suggested by $T / S$ peaks, lower gas and radiogenic helium contents and lower radionuclide activities.

a pre-determined schedule; the coincidence of the water sampling (i.e. the geochemical datum) with the $T-S$ peaks is therefore only casual, with shifts variable of several hours.

It is not possible therefore to make a point-topoint correlation but from a detailed examination of all the time-series data and as it appears in figs. 3,4 and 6 , it is possible to observe that:

- Samples relatively far or prior to $T-S$ peaks have higher gas concentration, more $\mathrm{He}$ radiogenic and higher radioactivity.

- Samples taken the same day or just some tens of hours after $T-S$ peaks have gases and $\mathrm{He}$ isotopic ratio closer to atmospheric equilibrium and lower radionuclide concentration.

Only two helium data, 10 December and 8 February, do not respect this pattern displaying atmospheric signature far or before $T-S$ peaks. Moreover all geochemical data seem to not be influenced by the $T-S$ peak no. 5, which is, indeed, the shortest event.

It is possible to argue that during or close to the major events of $T-S$ variation the gas and radionuclide content decreases and the $\mathrm{He}$ isotopic ratio increases. This fact would support the interpretation of the CTD peaks as due to the vertical oscillation of the interface of two different water masses, close to the seafloor (fig. 8). Events of lower $\mathrm{He}$ and radionuclides, and higher $\mathrm{R} / \mathrm{Ra}$ (closer to the atmospheric ratio) would reflect the sinking of a less deep water (EOW). However we can think about this water mass either of having been less deep, although still not in contact with the atmosphere, or as a younger water mass (having been more recently at the surface in its zone of formation). The deeper water (WW), likely with higher age, has higher gas content and radioactivity and a lower He isotopic ratio, with more significant radiogenic component. The enrichment of radionuclides such as ${ }^{226} \mathrm{Ra}$ in deep-sea waters due to diffusion from sediments is a wellknown phenomenon (e.g., Nozaki, 1986). Figures 5 and 7 show clearly the two water masses. This distinction is less marked by $\mathrm{CO}_{2}$ and $\mathrm{CH}_{4}$, which may have sources and sinks within the seawater column (and therefore a lower or nil difference between «seabed» signature and oceanic background) and the data can suffer higher biases from sampling to analysis.

\section{Conclusions}

The GEOSTAR 2 data-set represents the first long-term multidisciplinary monitoring of deep BBL including altogether seawater temperature, salinity, light transmission, 3D current, gas concentration, helium isotopes and radioactivity. The various geochemical and oceanographic data are basically coherent converging towards the indication of a BBL mainly characterised by a colder and fresher western water which is episodically displaced by the cascading of a warmer and saltier eastern water.

The colder fresher water has higher concentrations of elements produced in the lithosphere (helium, radionuclides and partially methane and carbon dioxide), likely due also to a higher benthic residence time. The warmer saltier water has geochemical features typical of ocean background.

The geochemical data, although potentially affected by sampling and analytical biases, suggest that gas and radionuclides in BBL seawater, deriving from Earth degassing and diffusion from sediments, can be useful tracers to distin- 
guish water masses of different origin and benthic residence times. GEOSTAR-2 demonstrated the potential of long-term, continuous multiparametric monitoring in providing unique information which cannot be acquired by traditional, short-term or single-sensor investigations.

\section{REFERENCES}

ArPesella, C. (1996): A low background counting facility at Laboratori Nazionali del Gran Sasso, Appl. Rad. Isot., 47, 991-996.

Beranzoli, L., A. De Santis, G. Etiope, P. Favali, F. FruGONI, G. SMriglio, F. Gasparoni and A. MARigo (1998): GEOSTAR: a GEophysical and Oceanographic STation for Abyssal Research, Phys. Earth Planet. Inter, 108, 175-183.

Beranzoli, L., T. Braun, M. Calcara, D. Calore, R. Campaci, J.-M. Coudeville, A. De Santis, G. Etiope, P. Favali, F. Frugoni, J.-L. Fuda, F. Gamberi, F. Gasparoni, H.W. Gerber, M. Marani, J. Marvaldi, C. Millot, P. Palangio, G. Romeo and G. Smriglio (2000): European seafloor observatory offers new possibilities for deep-sea study, Eos, Trans. Am. Geophys. Un., 81 (5), 45 and 48.

Beranzoli, L., P. Favali and G. Smriglio (Editors) (2002): Science-technology synergy for research in marine environment: challenges for the XXI century, Developments in Marine Technology Series (Elsevier, Amsterdam), 12, pp. 268.

Boudreau, B.P. and B.B. Jorgensen (Editors) (2000): The Benthic Boundary Layer: Transport Processes and
Biogeochemistry (Oxford University Press), pp. 440.

Etiope, G. (1997): Evaluation of a micro-gas chromatographic technique for environmental analyses of $\mathrm{CO}_{2}$ and $\mathrm{C}_{1}-\mathrm{C}_{6}$ alkanes, J. Chromatogr. A, 775, 243-249.

Fuda, J.-L., G. Etiope, C. Millot, P. Favali, M. Calcara, G. SMriglio and E. Boschi (2002): Warming, salting and origin of the Tyrrhenian deep water, Geophys. Res. Lett., 29, doi: 1029/2001GL014072.

InN, K.G.W., Zhichao Lin, Zhongyu Wu, C. McMahon, J.J. Filliben, P. Krey, M. Feiner, Chung-King Liu, R. Holloway, J. Harvey, L. Larsen, T. Beasley, C.A. Huh, S. Morton, D. McCurdy, P. Germain, J. Handl, M. Yamamoto, B. Warren, T.H. Bates, A. Holms, B.R. Harvey, D.S. Popplewell, M.J. Woods, S. JeroMe, K.J. Odell, P. Young and I. Croudace (2001): The NIST natural-matrix radionuclide standard reference material program for ocean studies, J. Radioanal. $\mathrm{Nu}$ cl. Chem., 248 (1), 227-231.

NOZAKI, Y. (1986): ${ }^{226} \mathrm{Ra}^{222} \mathrm{Rn}-{ }^{210} \mathrm{~Pb}$ systematics in seawater near the bottom of the ocean, Earth Planet. Sci. Lett., 80, 36-40.

Plastino, W., M. Laubenstein, G. Etiope and P. Favali (2003): Environmental radioactivity analysis in seawater samples collected by GEOSTAR deep-sea observatory (Istituto Nazionale di Fisica Nucleare, Laboratori Nazionali del Gran Sasso), Annual Rep. 2002, 201206.

Sparnocchia, S., G.P. Gasparini, M. Astraldi, M. BorGHINI and P. PISTECK (1999): Dynamics and mixing of the Eastern Mediterranean outflow in the Tyrrhenian Basin, J. Mar. Syst., 20, 301-317.

Thiel, H., K.O. Kirstein, C. Luth, U. Luth, G. Luther, L.A. Meyer-Reil, O. Pfannkuche and M. Weydert (1994): Scientific requirements for an abyssal benthic laboratory, J. Mar Syst., 4, 421. 